\title{
Biomarkers in Patients with Left Ventricular Assist Device: An Insight on Current Evidence
}

\author{
Carlotta Sciaccaluga ${ }^{*}{ }^{\dagger}$, Nicolò Ghionzoli ${ }^{\dagger}$, Giulia Elena Mandoli ${ }^{D}$, Flavio D’Ascenzi, Marta Focardi, \\ Serafina Valente and Matteo Cameli (i)
}

check for

updates

Citation: Sciaccaluga, C.; Ghionzoli,

N.; Mandoli, G.E.; D'Ascenzi, F.; Focardi, M.; Valente, S.; Cameli, M. Biomarkers in Patients with Left Ventricular Assist Device: An Insight on Current Evidence. Biomolecules 2022, 12, 334. https://doi.org/ 10.3390/biom12020334

Academic Editor: Vladimir N. Uversky

Received: 30 December 2021 Accepted: 16 February 2022 Published: 19 February 2022

Publisher's Note: MDPI stays neutral with regard to jurisdictional claims in published maps and institutional affiliations.

Copyright: (c) 2022 by the authors. Licensee MDPI, Basel, Switzerland. This article is an open access article distributed under the terms and conditions of the Creative Commons Attribution (CC BY) license (https:/ / creativecommons.org/licenses/by/ $4.0 /)$.

\author{
Department of Medical Biotechnologies, Section of Cardiology, University of Siena, 53100 Siena, Italy; \\ nicologhionzoli@gmail.com (N.G.); giulia_elena@hotmail.it (G.E.M.); flaviodascenzi@gmail.com (F.D.); \\ focardim@unisi.it (M.F.); seravale@gmail.com (S.V.); matteo.cameli@yahoo.com (M.C.) \\ * Correspondence: carlotta.sciaccalauga@gmail.com; Tel.: +39-057-758-5377 \\ + These authors contributed equally to this work.
}

\begin{abstract}
Left ventricular assist devices (LVADs) have been representing a cornerstone therapy for patients with end-stage heart failure during the last decades. However, their use induces several pathophysiological modifications which are partially responsible for the complications that typically characterize these patients, such as right ventricular failure, thromboembolic events, as well as bleedings. During the last years, biomarkers involved in the pathways of neurohormonal activation, myocardial injury, adverse remodeling, oxidative stress and systemic inflammation have raised attention. The search and analysis of potential biomarkers in LVAD patients could lead to the identification of a subset of patients with an increased risk of developing these adverse events. This could then promote a closer follow-up as well as therapeutic modifications. Furthermore, it might highlight some new therapeutic pharmacological targets that could lead to improved long-term survival. The aim of this review is to provide current evidence on the role of different biomarkers in patients with LVAD, in particular highlighting their possible implications in clinical practice.
\end{abstract}

Keywords: LVAD; biomarkers; neurohormonal activation; adverse remodeling; inflammation

\section{Introduction}

Left ventricular assist devices (LVADs) have been representing a cornerstone therapy for patients with end-stage heart failure (HF) during the last decades, being able to face the growing shortage of heart donations on one hand and on the other hand to serve as an alternative in presence of contraindications to a heart transplant, that to date remains the gold standard [1]. Despite a progressive improvement of LVAD patients' survival, the medium- and long-term follow-up is jeopardized by a series of complications that have a great impact on prognoses, such as right ventricular failure, bleedings and thromboembolic events $[2,3]$. Some are determined by natural disease progression (i.e., right ventricular failure), others depend either on the switch of circulation and on compelling drugs used in order to prevent thromboembolic events. Indeed, despite amelioration in materials, these patients still need to be both on effective vitamin $\mathrm{K}$ antagonists and on single antiplatelet drugs to avoid surface thrombosis. Even though several hypotheses have been formulated, the exact pathophysiological mechanisms underlying major complications in LVAD recipients are still partially unknown. During the last years, biomarkers involved in the pathways of neurohormonal activation, myocardial injury, adverse remodeling, oxidative stress and systemic inflammation have raised attraction. Despite the extensive studies performed in the setting of HF, their role in patients with LVAD is still far from being clear. Indeed, LVAD profoundly alters the physiology of the whole cardiovascular system since its main function is to draw blood from the left ventricle and pump it back in the ascending aorta (or in rare cases in the descending aorta), by-passing the aortic valve, in order to reduce the pressure and the work of the failing left ventricle. Furthermore, new generation 
devices overturn normal circulation since they provide a continuous circulation rather than a pulsatile one, leading to several cellular and molecular adaptations. As a consequence, the traditional biomarkers that are well-studied in advanced heart failure might not be suitable for this set of patients, which could potentially lead to misinterpretations in clinical practice. To the best of our knowledge, there is no comprehensive review exploring the role of several biomarkers in LVAD patients and their link to complications development. The aim of this review is to provide current evidence on the role of different biomarkers in patients with LVAD, as exemplified in Figure 1, in particular highlighting their possible implications in clinical practice, especially for what concerns disease progression, early diagnosis of complications and prognostic evaluation.

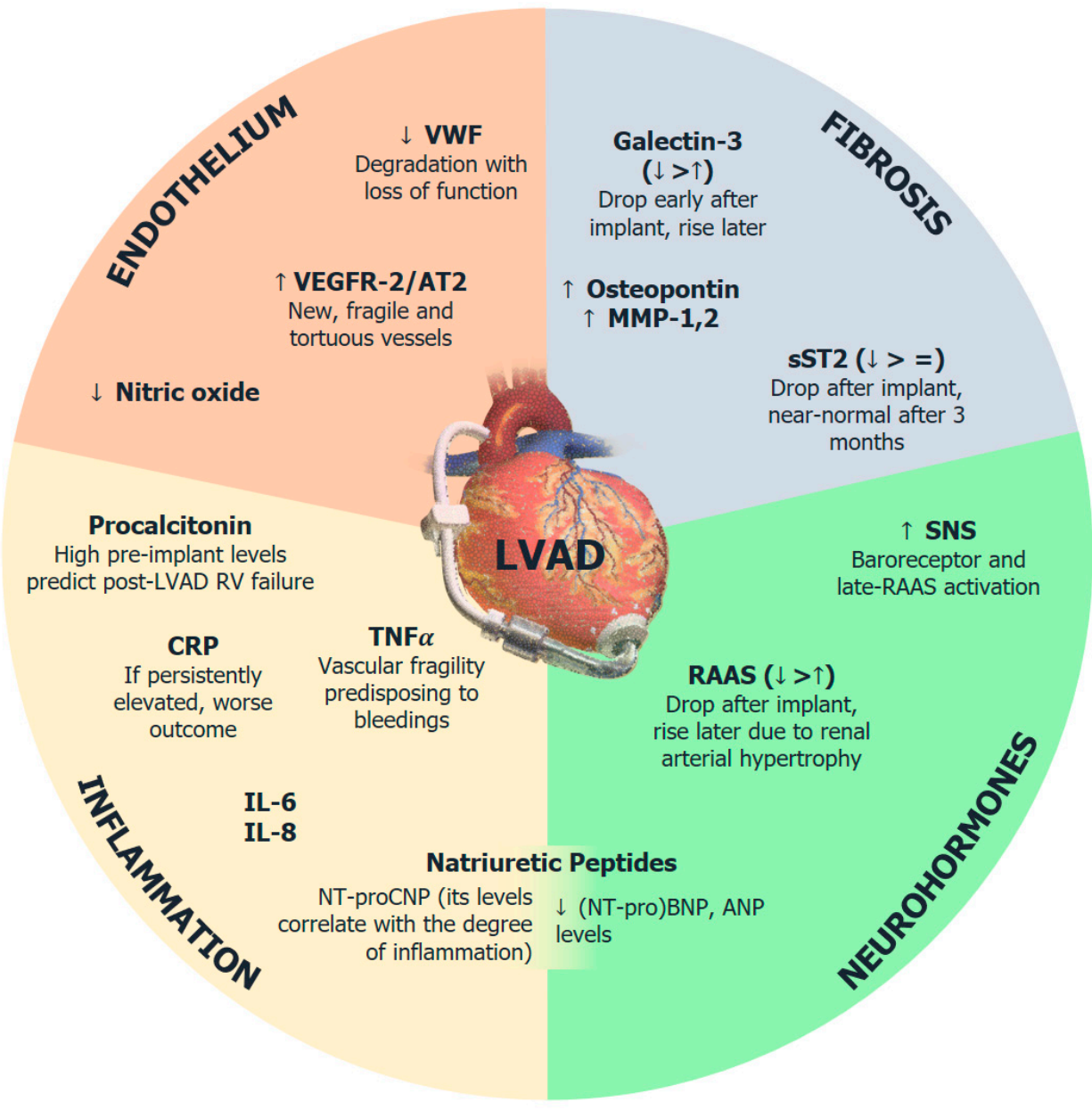

Figure 1. The spectrum of biomarker expression in patients with left ventricular assistance device (LVAD). Four patterns of biomarkers are here reported, with a brief description for each subgroup of the following: endothelium-, fibrosis-, inflammation-related markers and neurohormones. AT2, angiotensin receptor 2; CRP, C-reactive protein; IL, interleukin; LVAD, left ventricular assistance device; NT-proBNP, N-terminal fragment of precursor of B-type natriuretic peptide; NT-proCNP, N-terminal fragment of precursor of C-type natriuretic peptide; RAAS, renin-angiotensin-aldosterone system; $\mathrm{RV}$, right ventricle; SNS, sympathetic nervous system; sST2, soluble suppression of tumorigenesis 2; TNF, tumor necrosis factor; VEGF, vascular endothelial growth factor; vWF, von Willebrand factor.

We included not only the most studied and available markers in LVAD patients, but we also provided an overview of novel and original biomarkers, even though their actual use in clinical practice is still marginal. Intriguingly, as explained further on, there is a notable overlap in deranged mechanisms responsible for disease progression between advanced $\mathrm{HF}$ and post-LVAD implantation, despite drivers for their activation may consistently differ. 


\section{Neurohormonal Activation}

\subsection{Sympathetic Nervous System}

The first-generation LVADs were characterized by a pulsatile flow, mimicking physiologic circulation. This type of flow was associated with a decreased renin-angiotensinaldosterone system (RAAS) functioning, reducing, in turn, RAAS-dependent sympathetic nervous system (SNS) activation [4]. Despite being more physiological, these devices had lower durability, required larger external leads (increasing infective risk) and extensive surgical dissection, and were noisier [5].

Continuous-flow LVADs instead revolutionized the clinical management of this cohort of patients, at the price of a deep change in circulation. The continuous flow reduces baroreceptor stimulation, thus, leading to sympathetic stimulation to a greater extent [6]. This mechanism can be further enhanced depending on the residual myocardial activity: if the patient is fully dependent on LVAD-induced circulation, the aortic valve will remain closed, further blunting the excursion of the aortic wall and impairing baroreceptor stimulation [7].

Sympathetic overstimulation during LVADs causes in the early phase an increase in cardiac angiotensin I and angiotensin II levels [4], thus, promoting cardiac SNS activity in a vicious circle. In later phases, chronic overstimulation favors juxta-glomerular and afferent arterial vascular smooth muscle cell proliferation, reducing stretch sensitivity and, in turn, increasing RAAS activity, despite the partial restoration of hemodynamic functions [8]. However, SNS blockade together with LVAD device seems to promote cardiac sympathetic reinnervation, as demonstrated with meta-iodo-benzyl-guanidine scintigraphy in a population of patients with idiopathic dilated cardiomyopathy [9]. Cardiac reinnervation, in turn, has been shown to be a marker of functional recovery after LVAD implantation [10].

Whether these observations affect mortality or the incidence of cardiovascular events, remains mostly unsolved. Little is known also regarding the actual impact of quality of life. A study of cardiopulmonary exercise tests demonstrated an inverse relationship between norepinephrine circulating levels and anaerobic threshold and oxygen pulse, but their levels did not correlate with peak oxygen consumption [11]. Besides, the exercise-induced increase in blood pressure is blunted in patients with LVAD, despite the increase in the pulsatile component related to the intrinsic ventricular activity [12]. LVAD-dependent blood flow is only mildly increased during exercise, as current devices cannot adjust flow depending on peripheral requests [13].

Some biomarkers also seem to predict the clinical outcome before LVAD implantation, especially concerning quality of life. LVAD responders have low levels of $\beta$-adrenergic receptor kinase, which would promote internalization/desensitization of $\beta$ receptors, and high levels of dihydroxyphenylglycol, a catabolite of norepinephrine. High levels of this molecule, with consequent ratio norepinephrine/dihydroxyphenylglycol approximately to 1, point out an active, capable process of catecholamines degradation, and thus, lower exposure [14]. Intriguingly, norepinephrine levels were comparable between responders and non-responders.

\subsection{Renin-Angiotensin-Aldosterone System}

Whilst pulsatile flow from first generation LVAD reduced RAAS activation, new generation, continuous flow LVAD devices cause chronic stimulation of the axis on a mid-to-long-term basis. Immediately after LVAD implantation, blood pressure normalizes and circulating RAAS is diminished. This, in turn, reduces cardiac levels of renin and aldosterone, so that angiotensinogen is no longer rapidly depleted. As a result, myocardial levels of angiotensin I and II are increased, thus activating the SNS. On the other hand, continuous flow induces media wall hypertrophy, blunting mechanical stretch on mechanoreceptors and activating RAAS. Furthermore, myocardial collagen content and cross-linking are increased under LVAD, despite mechanical unloading. Figure 2 shows the interplay between RAAS and the SNS in patients after LVAD implantation. 


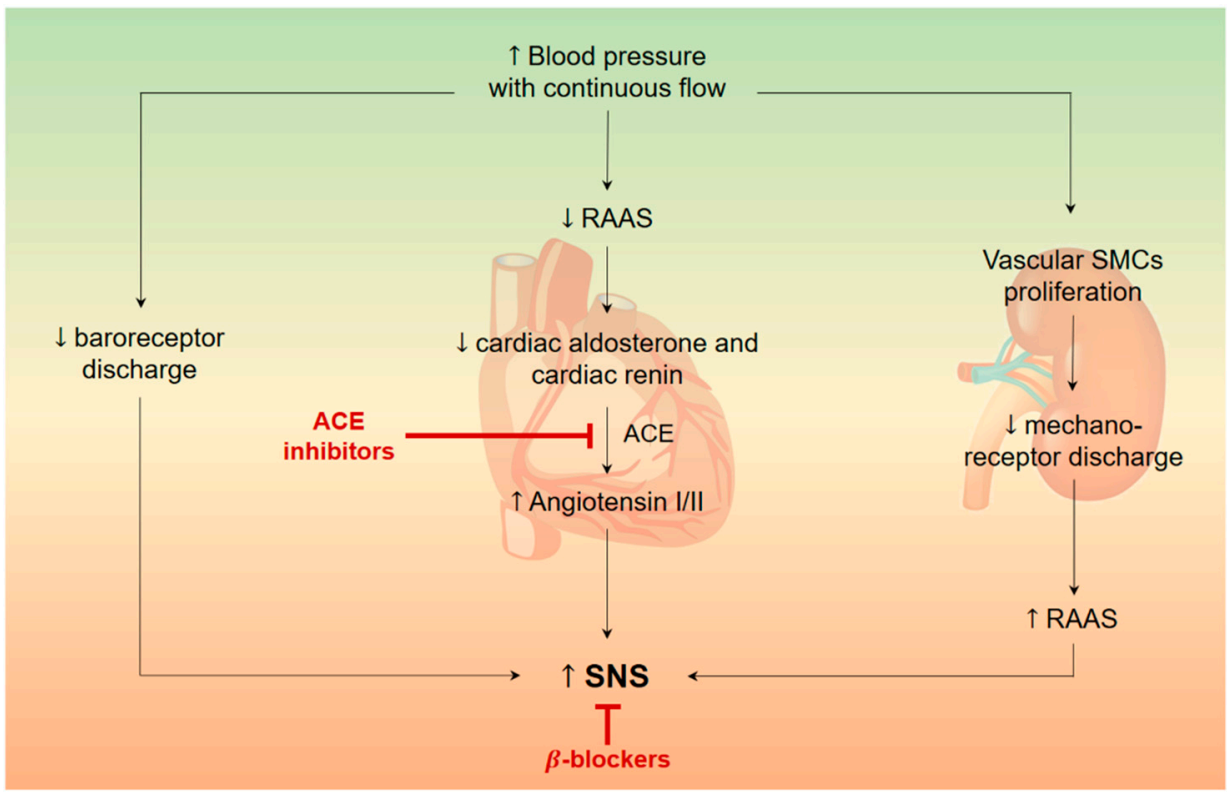

Figure 2. The interplay between renin-angiotensin-aldosterone system (RAAS) and sympathetic nervous system (SNS) in patients after left ventricular assistance device (LVAD). The LVAD-induced continuous flow reduces baroreceptor discharge, thus increasing SNS activity. This is further enhanced by the increase of cardiac angiotensin II levels. Long-term continuous flow induces vascular smooth muscle cells (vSMCs) proliferation with RAAS and further SNS activation. ACE, angiotensinconverting enzyme; RAAS, renin-angiotensin-aldosterone system; SNS, sympathetic nervous system.

These phenomena are intuitively mitigated by the use of angiotensin converting enzyme inhibitors (ACEi), including the cross linking of collagen fibers $[4,15]$. This class of drugs, with or without the use of beta-blockers, was demonstrated to improve survival in a cohort of patients with LVAD [16]. However, the only use of mineralocorticoid receptor antagonists (MRA) did not improve survival, but patients on triple therapy (beta-blockers, ACEi and MRA) showed the best survival rate [17].

\subsection{Natriuretic Peptide System}

An increasing amount of studies is assessing the role of the natriuretic peptide (NP) system in patients with LVAD, including the use of ARNI in this population. These molecules have been studied both in systemic and local myocardial settings. Several studies demonstrated that LVAD implantation reduces circulating levels of N-terminal pro-B-type natriuretic peptide (NT-proBNP) [18], B-type natriuretic peptide (BNP) $[19,20]$ and atrial natriuretic peptide (ANP) [19]. In a retrospective, single-center study of 63 patients, pulmonary capillary wedge pressure was the only independent predictor of NT-proBNP levels after LVAD implantation [21]. Furthermore, in animal models of LVAD, the secretion of ANP in response to an increase in central venous pressure was preserved [22]. However, the increase in central venous pressure leads to higher renal interstitial pressure, with increased renin release. The use of ARNI in the setting of LVAD, favored by the restored hemodynamic functions, reduced NT-proBNP plasma level, without altering serum levels of potassium, creatinine and blood urea nitrogen [23]. N-terminal pro-C-type natriuretic peptide (NT-proCNP) raised progressive attention, as it is mainly produced by endothelial cells and its levels are higher in non-surviving, LVAD-implanted patients. It also positively correlates with a greater inflammatory response [24]. As a consequence, the pro-inflammatory activation of the endothelium may be responsible for a worse clinical outcome, with multi-organ dysfunction. Furthermore, NPs may have a role in the pre-implantation setting for the correct selection of candidates. Pre-LVAD BNP levels predict right ventricular failure $>48 \mathrm{~h}$ after implantation and correlate with the occurrence of ventricular arrhythmias postoperatively [25], whereas NT-proBNP levels predict early right ventricular failure $(<48 \mathrm{~h})$. Both molecules can also predict major 
adverse events, as well as re-hospitalization until 1.5 years from implantation. Unfortunately, to date, no NP demonstrated to predict all-cause mortality nor left ventricular recovery [26]. NPs can also exert a paracrine/autocrine role. Under physiologic circumstances, the axis of $\mathrm{NP}$ /guanylate cyclase (GC)-A/cyclic guanosine monophosphate prevents myocardial fibrosis and hypertrophy [27]. Knock-out mice for BNP develop cardiac fibrosis without an increase in blood pressure [28]. In LVAD recipients, chronic unloading can restore the correct genotype expression, with normalization of ANP/BNP ratio, GC-A/natriuretic peptide receptor-C ratio (17 di observ8) and recovery of GC-A response to ANP [29].

\section{Markers of Myocardial Fibrosis}

As collagen content does not decrease after LVAD implantation, a focus grew on biomarkers of fibrosis. Soluble suppressor of tumorigenicity 2 (sST2) has been widely investigated in $\mathrm{HF}$, both in acute and chronic settings, and despite its use in clinical practice is still missing. In patients with end-stage HF, its levels correlate with the severity of the disease, being higher in INTERMACS I rather than in classes II and III [30]. It holds higher prognostic performance than BNP and NT-proBNP (4 di sST2), and its levels at the time of LVAD surgery [31], as well as interleukin-6 ones [32], have been associated with an increased risk of developing multiorgan failure postoperatively. Circulating levels of sST2 drop after LVAD implantation, with the greatest extent after 1 month and with near-normal levels after 3 months [33].

Galectin-3, a paracrine molecule secreted by macrophages, is directly involved in cardiac fibrosis via TGF- $\beta$ signaling pathway $[34,35]$. Despite the number of studies in $\mathrm{HF}$, its role in LVAD recipients in nebulous. First, data found a significant drop immediately after the implantation of the device, as a response to hemodynamic unloading. However, at the time of explant, its levels arise near to pre-implantation values, as if chronic mechanical support would promote inflammation and fibrosis [36,37]. Pre-implantation galectin-3 values may predict the outcome, but the evidence is weak and further studies are demanded [36]. When using NT-proBNP reduction $>25 \%$ as a surrogate of hemodynamic improvement, galectin-3 was the only biomarker showing a significant reduction.

Finally, persistently elevated markers of extracellular matrix turnover (osteopontin, tissue inhibitors of matrix metalloprotein-1 and matrix metalloprotein-2) [38], together with neurohumoral activation (endothelin-1, NT-proBNP), inflammation (neopterin, procalcitonin) [39] and neutrophil gelatinase-associated lipocalin (NGAL) [40], identify advanced HF patients who will likely develop right ventricular failure after LVAD implantation. Specifically, pre-implantation osteopontin levels $>259.2 \mathrm{ng} / \mathrm{mL}$ predict the development of right ventricular failure after LVAD implantation [38]. However, many of these markers reflect target organ dysfunction and are not specific to the right ventricle. Figure 3 tries to exemplify the trajectories of neuro-hormonal and fibrotic systems in patients before and after LVAD implantation. 


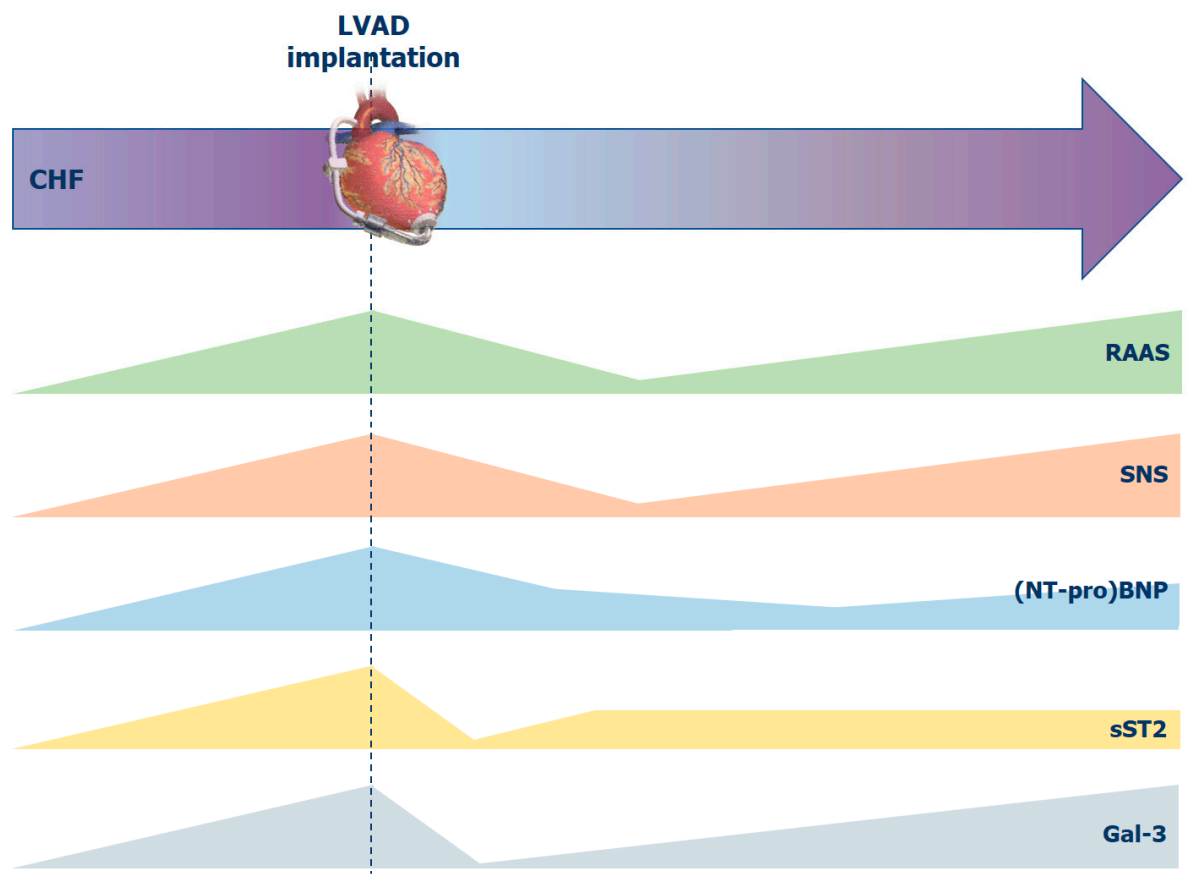

Figure 3. Trajectories of neuro-hormonal and fibrotic systems in patients before and after left ventricular assist device (LVAD) implantation. A figurative timeline is represented above. All markers have the highest levels right before the LVAD implant, but they have different trends afterward. Specific causes for biomarkers elevation/reduction are reported in the text. BNP, B-type natriuretic peptide; CHF, chronic heart failure; Gal-3, galectin-3; LVAD, left ventricular assist device; NT, Nterminal; RAAS, renin-angiotensin-aldosterone system; SNS, sympathetic nervous system; sST2, soluble suppression of tumorigenicity 2.

\section{Endothelial Dysfunction and Neoangiogenesis}

The last generation continuous flow LVADs expose the endothelium to increased shear stress which breaks the balance of angiogenetic factors, leading to anomalous vessel development, mucosal hypervascularity and angiodysplasia [41,42]. Therefore, the loss of pulsatility seems to be responsible for gastrointestinal bleeding, which represents one of the main long-term complications in this cohort of patients. In support of this, several in vitro studies demonstrated that the plasma of patients with continuous LVAD shows abnormal levels of angiogenic peptides [41,43], reflecting deregulation in angiogenesis. The underlying mechanisms are still not fully known. However, it has been proven that the anomalous shear stress induces an accelerated degradation of von Willebrand factor (vWF) [44].

vWF is a glycoprotein synthesized by both endothelial cells and megakaryocytes, which is released when a hemorrhage occurs, contributing to the creation of the platelet plug within the vessel. High-molecular-weight multimers of vWF are characterized by a higher hemostatic potential and are degraded by ADAMS-13 in smaller multimers. Several studies reported that the shear stress caused by continuous flow makes the high-molecularweight multimers of vWF more susceptible to their degradation, leading to increased levels of circulating smaller multimers, causing acquired vWF syndrome, whose incidence is elevated in LVAD patients [45]. Even though the precise effects of elevated levels of circulating $\mathrm{vWF}$ are not completely established, the association between acquired $\mathrm{vW}$ syndrome, angiodysplasia and bleeding events seems to have a clinical confirmation not only in this set of patients but also in other clinical conditions, such as Heyde syndrome [46]. In fact, even though the hemostatic role of $\mathrm{vWF}$ is well-consolidated, there is growing evidence of its involvement in the regulation of several vascular pathways, including angiogenesis [47,48]. One of the most studied pathways is the signaling mediated by vascular endothelial growth factor (VEGF) receptor-2 and angiotensin-2. Indeed, both angiotensin 1 and 2 are molecules 
implicated in angiogenesis regulation. Angiotensin-1 is synthesized by perivascular cells and it promotes vascular maturity together with normal vessel development. On the other hand, angiotensin-2 is exclusively synthesized by endothelial cells and is stored into Weibel-Palade bodies together with vWF. Once it is released, it competes with angiotensin1 for tyrosine-kinase Tie2 receptor and, together with VEGF, it promotes a dysregulated angiogenesis characterized by fragile and tortuous vessels [49]. Tabit CE et al. reported elevated circulating levels of angiotensin-2 and a higher expression of angiotensin- 2 on endothelial cells in patients with LVAD [41]. This increment might be partially explained by the activation of protease-activated receptor-1 (PAR-1) mediated by thrombin, whose levels tend to be augmented in these patients [50], promoting angiotensin-2 overproduction [41]. In addition to that, Tabit CE et al. highlighted the association between circulating levels of angiotensin-2 and non-surgical bleeding [41].

If on one hand, the loss of pulsatile flow conveys a higher predisposition to bleedings, especially from the gastrointestinal tract, on the other hand, it seems implicated in greater coagulability, leading to a greater tendency for thromboembolic events. In fact, in the presence of continuous flow, end-organ perfusion relies upon both systemic and local regulatory mechanisms. In this context, local mediators play a key role in the endothelium, which in turn are influenced by the characteristics of the blood flow. Non-pulsatile blood flow reduces the release of nitric oxide, one of the principal local vasodilators [51]. Patients with a continuous flow LVAD are characterized by endothelial dysfunction, especially in the microvasculature, which, in turn, triggers an inflammatory response that finally leads to an increased thromboembolic risk.

\section{Systemic Inflammation}

It has been widely demonstrated that the plasmatic levels of inflammatory cytokines, such as tumor-necrosis factor- alfa (TNF-alfa) and interleukin-6 (IL-6), are elevated in chronic HF patients [52-54] and they correlate with both the severity of symptoms and the disease, as well as with prognosis [53,54]. In addition to that, in the early stages after LVAD implant, the elevation of inflammation indexes is correlated with higher mortality $[55,56]$. In support of this, Henning et al. suggested a possible correlation between elevated pre-operative procalcitonin levels with the onset of right ventricular failure post-LVAD implant [39]. Furthermore, Caruso R et al. attested that systemic inflammation, identified by several biomarkers like IL-6, IL-8 and C-reactive protein (CRP), is related to the development of multi-organ failure in the postoperative period $[46,47]$. The possible mechanisms implicated in the up-regulation of the inflammatory pathways in LVAD patients are still unknown, even though several physiopathological hypotheses have been proposed.

One potential explanation is based on the evidence that when blood encounters a foreign surface, such as the device, it triggers intracellular pathways that finally lead to the release of several chemokines like macrophage inflammatory proteins-1beta (MIP-1beta), granulocyte macrophage-colony stimulating factor (GM-CSF), IL-8, interferon-gamma-induced protein-10 (IP-10) and monocyte chemoattractant protein-1 (MCP-1) [57,58]. Among these biomarkers, a relevant role is played by TNF-alfa. In fact, elevated levels of TNF-alfa are associated with vascular destabilization mediated by pericyte apoptosis together with angiopoietin-1 suppression, giving rise to an augmented risk of bleedings [31]. Indeed, evidence suggests that this cytokine is involved in the pathogenesis of angiodysplasia which is fairly common in these patients [59].

Another explanation is instead based on the fact that both foreign bodies and increased shear stress promote platelet activation and dysfunction which, in turn, favors the formation of platelet-neutrophil conjugates, which are proven to be inflammatory actors in sepsis and ischemia-reperfusion events [60]. Even though CRP is the most commonly used marker of systemic inflammation in clinical practice, its role has been under investigated in the LVAD population. However, some studies reported higher CRP levels after LVAD implant [61] while others attested its negative prognostic role in case of persistently increased values, due to their correlation with organ dysfunction [55]. 
Finally, a third explanation relies on the change of blood flow from pulsatile to continuous. In fact, in animal models, it was shown that this change implicates a hyperactivation of the renin-angiotensin-aldosterone system [62], which was then confirmed in humans through elevated levels of both aldosterone and plasma renin activity in patients with continuous flow-LVAD compared to previous generation pulsatile flow-LVAD [63]. This implies elevated levels of angiotensin-II and aldosterone and so increased circulating inflammatory cytokines, such as TNF-alfa, IL-6, IL-8 and CRP [64]. Despite these premises, Grosman-Rimon et al. demonstrated how systemic chronic inflammatory persists regardless of the use of neurohormonal blocking agents, suggesting that alternative mechanisms might be involved in the genesis of inflammation [64].

The effective clinical implications of these biomarkers have not been completely elucidated. However, the investigation of the relationship between these continuous flows devices, inflammatory status and the relative cytokines might be particularly relevant since they seem to correlate with myocardial $[65,66]$ and vascular alterations $[67,68]$ potentially adding further elements in the pathophysiology of postoperative complications, as well as potentially providing future therapeutic targets.

As mentioned above, bleeding predisposition is frequently accompanied by thromboembolic susceptibility in LVAD patients. In fact, inflammatory status favors bleeding events due to altered angiogenesis and angiodysplasia development, but it also predisposes patients to thrombotic complications through the inhibition of antithrombotic agent release, such as antithrombin and $C$ protein, creating a procoagulant state [69,70]. Both of them are implicated in regulatory pathways of thrombin genesis, which is over-produced in LVAD patients [50]. Different studies showed that patients with pump thrombosis had higher systemic inflammation status with three to four fold higher CRP levels compared to patients without pump thrombosis [69].

\section{Conclusions}

LVAD patients represent a fragile population, susceptible to several complications both in the short-, medium- and long-term, attributable to pathophysiological modifications induced by continuous flow, to the characteristics of the device and its biocompatibility, as well as the required anti-thrombotic therapy. If on one hand the device allows left ventricular unloading and improvement of end-organ perfusion, on the other, it determines profound alterations in physiological balance. In fact, hemodynamic improvement and potential myocardial recovery are not necessarily parallel with the restoration of a normal molecular and cellular physiology. Indeed, the most relevant complications in terms of prognosis and health burden are right ventricular failure, bleedings and thromboembolic events, that are caused by specific mechanisms with their underlying mediators and molecular pathways. The search and analysis of potential biomarkers in LVAD patients could lead to the identification of a subset of patients with an increased risk of developing these adverse events. This could then promote a closer follow-up as well as therapeutic modifications. Furthermore, it might highlight some new therapeutic pharmacological targets that could lead to improved long-term survival.

Author Contributions: Conceptualization, C.S. and M.C.; writing-original draft preparation, C.S. and N.G.; writing-review and editing, M.C., M.F., F.D., G.E.M. and S.V.; visualization, N.G.; supervision, M.C. All authors have read and agreed to the published version of the manuscript.

Funding: This research received no external funding.

Institutional Review Board Statement: Not applicable.

Informed Consent Statement: Not applicable.

Data Availability Statement: Not applicable.

Conflicts of Interest: The authors declare no conflict of interest. 


\section{References}

1. Han, J.J.; Acker, M.A.; Atluri, P. Left Ventricular Assist Devices. Circulation 2018, 138, 2841-2851. [CrossRef] [PubMed]

2. Mehra, M.R. The burden of haemocompatibility with left ventricular assist systems: A complex weave. Eur. Heart J. 2019, 40, 673-677. [CrossRef] [PubMed]

3. Pagani, F.D. Right Heart Failure After Left Ventricular Assist Device Placement: Medical and Surgical Management Considerations. Cardiol. Clin. 2020, 38, 227-238. [CrossRef] [PubMed]

4. Klotz, S.; Burkhoff, D.; Garrelds, I.M.; Boomsma, F.; Danser, A.J. The impact of left ventricular assist device-induced left ventricular unloading on the myocardial renin-angiotensin-aldosterone system: The rapeutic consequences? Eur. Heart J. 2009, 30, 805-812. [CrossRef]

5. Long, J.W.; Kfoury, A.G.; Slaughter, M.S.; Silver, M.; Milano, C.; Rogers, J.; Delgado, R.; Frazier, O.H. Long-term destination therapy with the HeartMate XVE left ventricular assist device: Improved outcomes since the REMATCH study. Congest Heart Fail. 2005, 11, 133-138. [CrossRef]

6. Markham, D.W.; Fu, Q.; Palmer, M.D.; Drazner, M.H.; Meyer, D.M.; Bethea, B.T.; Hastings, J.L.; Fujimoto, N.; Shibata, S.; Levine, B.D. Sympathetic Neural and Hemodynamic Responses to Upright Tilt in Patients with Pulsatile and Nonpulsatile Left Ventricular Assist Devices. Circ. Heart Fail. 2013, 6, 293-299. [CrossRef]

7. Cowger, J.; Pagani, F.D.; Haft, J.W.; Romano, M.A.; Aaronson, K.D.; Kolias, T.J. The development of aortic insufficiency in left ventricular assist device-supported patients. Circ Heart Fail. 2010, 3, 668-674. [CrossRef]

8. Ohnishi, H.; Itoh, T.; Nishinaka, T.; Tatsumi, E.; Fukuda, T.; Oshikawa, M.; Shioya, K.; Tsukiya, T.; Takewa, Y.; Homma, A.; et al. Morphological changes of the arterial systems in the kidney under prolonged continuous flow left heart bypass. Artif. Organs. 2002, 26, 974-979. [CrossRef]

9. George, R.; Birks, E.J.; Cheetham, A.; Webb, C.; Smolenski, R.; Khaghani, A.; Yacoub, M.H.; Kelion, A. The effect of long-term left ventricular assist device support on myocardial sympathetic activity in patients with non-ischaemic dilated cardiomyopathy. Eur. J. Heart Fail. 2013, 15, 1035-1043. [CrossRef]

10. Drakos, S.G.; Athanasoulis, T.; Malliaras, K.G.; Terrovitis, J.V.; Diakos, N.; Koudoumas, D.; Ntalianis, A.S.; Theodoropoulos, S.P.; Yacoub, M.H.; Nanas, J.N. Myocardial Sympathetic Innervation and Long-Term Left Ventricular Mechanical Unloading. JACC Cardiovasc. Imaging 2010, 3, 64-70. [CrossRef]

11. Grosman-Rimon, L.; Kachel, E.; McDonald, M.A.; LaLonde, S.D.; Yip, P.; Ribeiro, R.V.; Adamson, M.B.; Cherney, D.Z.; Rao, V. Association Between Neurohormone Levels and Exercise Testing Measures in Patients with Mechanical Circulatory Supports. ASAIO J. 2019, 66, 875-880. [CrossRef] [PubMed]

12. Sailer, C.; Edelmann, H.; Buchanan, C.; Giro, P.; Babcock, M.; Swanson, C.; Spotts, M.; Schulte, M.; Pratt-Cordova, A.; Coe, G.; et al. Impairments in Blood Pressure Regulation and Cardiac Baroreceptor Sensitivity Among Patients with Heart Failure Supported With Continuous-Flow Left Ventricular Assist Devices. Circ. Heart Fail. 2021, 14, e007448. [CrossRef] [PubMed]

13. Moss, N.; Rakita, V.; Lala, A.; Parikh, A.; Roldan, J.; Mitter, S.S.; Anyanwu, A.; Campoli, M.; Burkhoff, D.; Mancini, D.M. Hemodynamic response to exercise in patients supported by continuous flow left ventricular assist devices. JACC Heart Fail. 2020, 8, 291-301. [CrossRef] [PubMed]

14. Denfeld, Q.E.; Lee, C.S.; Woodward, W.R.; Hiatt, S.O.; Mudd, J.O.; Habecker, B.A. Sympathetic Markers are Different between Clinical Responders and Nonresponders after Left Ventricular Assist Device Implantation. J. Cardiovasc. Nurs. 2019, 34, E1-E10. [CrossRef] [PubMed]

15. Klotz, S.; Danser, A.J.; Foronjy, R.F.; Oz, M.C.; Wang, J.; Mancini, D.; D’Armiento, J.; Burkhoff, D. The impact of angiotensinconverting enzyme inhibitor therapy on the extracellular collagen matrix during left ventricular assist device support in patients with end-stage heart failure. J. Am. Coll. Cardiol. 2007, 49, 1166-1174. [CrossRef] [PubMed]

16. Brinkley, D.M., Jr.; Wang, L.; Yu, C.; Grandin, E.W.; Kiernan, M.S. Impact of renin-angiotensin-aldosterone system inhibition on morbidity and mortality during long-term continuous-flow left ventricular assist device support: An IMACS report. J. Heart Lung Transplant. 2021, 40, 1605-1613. [CrossRef] [PubMed]

17. McCullough, M.; Caraballo, C.; Ravindra, N.G.; Miller, P.E.; Mezzacappa, C.; Levin, A.; Gruen, J.; Rodwin, B.; Reinhardt, S.; Van Dijk, D.; et al. Neurohormonal Blockade and Clinical Outcomes in Patients with Heart Failure Supported by Left Ventricular Assist Devices. JAMA Cardiol. 2020, 5, 175-182. [CrossRef]

18. Zabarovskaja, S.; Hage, C.; Linde, C.; Daubert, J.-C.; Donal, E.; Gabrielsen, A.; Mellbin, L.; Lund, L.H. Adaptive cardiovascular hormones in a spectrum of heart failure phenotypes. Int. J. Cardiol. 2015, 189, 6-11. [CrossRef]

19. Milting, H.; Banayosy, A.E.; Kassner, A.; Fey, O.; Sarnowski, P.; Arusoglu, L.; Thieleczek, R.; Brinkmann, T.; Kleesiek, K.; Körfer, $\mathrm{R}$. The time course of natriuretic hormones as plasma markers of myocardial recovery in heart transplant candidates during ventricular assist device support reveals differ- ences among device types. J. Heart Lung Transplant. 2001, 20, 949-955. [CrossRef]

20. Wagner, F.D.; Buz, S.; Zais, H.; Stasch, J.P.; Hetzer, R.; Hocher, B. Humoralandhemody- namic responses after left ventricular assist device implantation and heart trans- plantation. Exp. Biol. Med. 2006, 231, 861-864.

21. Knudsen, M.S.S.; Eismark, F.; Goetze, J.P.; Gustafsson, F.; Wolsk, E. The contribution of cardiac and extracardiac factors to NT-proBNP concentrations in patients with advanced heart failure before and after left ventricular assist device implantation. Peptides 2021, 135, 170420. [CrossRef] [PubMed]

22. Taenaka, Y.; Yagura, A.; Takano, H.; Matsuda, T.; Noda, H.; Kinoshita, M.; Takatani, S.; Akutsu, T. Altered humoral control of circulating volume during artificial circulation. ASAIO Trans. 1988, 34, 692-695. 
23. Alishetti, S.; Braghieri, L.; Jennings, D.L.; Uriel, N.; Colombo, P.C.; Yuzefpolskaya, M. Angiotensin receptor neprilysin inhibitor use in patients with left ventricular assist devices: A single-center experience. Int. J. Artif. Organs. 2022, 45, 118-120. [CrossRef] [PubMed]

24. Cabiati, M.; Caruso, R.; Caselli, C.; Frigerio, M.; Prescimone, T.; Parodi, O.; Giannessi, D.; Del Ry, S. The natriuretic peptide time-course in end-stage heart failure patients supported by left ventricular assist device implant: Focus on NT-proCNP. Peptides 2012, 36, 192-198. [CrossRef] [PubMed]

25. Hellman, Y.; Malik, A.S.; Lin, H.; Shen, C.; Wang, I.W.; Wozniak, T.C.; Hashmi, Z.A.; Pickrell, J.; Jani, M.; Caccamo, M.A.; et al B-Type Natriuretic Peptide Levels Predict Ventricular Arrhythmia Post Left Ventricular Assist Device Implantation. Artif. Organs. 2015, 39, 1051-1055. [CrossRef]

26. Imamura, T.; Kinugawa, K.; Nitta, D.; Kinoshita, O.; Nawata, K.; Ono, M. Preoperative iodine-123 meta-iodobenzylguanidine imaging is a novel predictor of left ventricular reverse remodeling during treatment with a left ventricular assist device. J. Artif. Organs. 2016, 19, 29-36. [CrossRef]

27. Kishimoto, I.; Rossi, K.; Garbers, D.L. A genetic model provides evidence that the receptor for atrial natriuretic peptide (guanylyl cyclase-A) inhibits cardiac ventricular myocyte hypertrophy. Proc. Natl. Acad. Sci. USA 2001, 98, 2703-2706. [CrossRef]

28. Tamura, N.; Ogawa, Y.; Chusho, H.; Nakamura, K.; Nakao, K.; Suda, M.; Kasahara, M.; Hashimoto, R.; Katsuura, G.; Mukoyama, M.; et al. Cardiac fibrosis in mice lacking brain natriuretic peptide. Proc. Natl. Acad. Sci. USA 2000, 97, 4239-4244. [CrossRef]

29. Kuhn, M.; Voß, M.; Mitko, D.; Stypmann, J.; Schmid, C.; Kawaguchi, N.; Grabellus, F.; Baba, H.A. Left ventricular assist device support reverses altered cardiac expression and function of natriuretic peptides and receptors in end-stage heart failure. Cardiovasc. Res. 2004, 64, 308-314. [CrossRef]

30. Bayes-Genis, A.; Zhang, Y.; Ky, B. ST2 and Patient Prognosis in Chronic Heart Failure. Am. J. Cardiol. 2015, 115, 64B-69B. [CrossRef]

31. Holzhauser, L.; Kim, G.; Sayer, G.; Uriel, N. The Effect of Left Ventricular Assist Device Therapy on Cardiac Biomarkers: Implications for the Identification of Myocardial Recovery. Curr. Hear. Fail. Rep. 2018, 15, 250-259. [CrossRef] [PubMed]

32. Caruso, R.; Botta, L.; Verde, A.; Milazzo, F.; Vecchi, I.; Trivella, M.G.; Martinelli, L.; Paino, R.; Frigerio, M.; Parodi, O. Relationship between Pre-Implant Interleukin-6 Levels, Inflammatory Response, and Early Outcome in Patients Supported by Left Ventricular Assist Device: A Prospective Study. PLoS ONE 2014, 9, e90802. [CrossRef] [PubMed]

33. Tseng, C.C.S.; Huibers, M.M.H.; Gaykema, L.H.; Koning, E.S.-D.; Ramjankhan, F.Z.; Maisel, A.S.; de Jonge, N. Soluble ST2 in end-stage heart failure, before and after support with a left ventricular assist device. Eur. J. Clin. Investig. 2018, 48 , e12886. [CrossRef] [PubMed]

34. Henderson, N.C.; Sethi, T. The regulation of inflammation by galectin-3. Immunol. Rev. 2009, 230, 160-171. [CrossRef]

35. A McCullough, P.; Olobatoke, A.; E Vanhecke, T. Galectin-3: A novel blood test for the evaluation and management of patients with heart failure. Rev. Cardiovasc. Med. 2011, 12, 200-210.

36. Coromilas, E.; Que-Xu, E.-C.; Moore, D.; Kato, T.S.; Wu, C.; Ji, R.; Givens, R.; Jorde, U.P.; Takayama, H.; Naka, Y.; et al. Dynamics and prognostic role of galectin-3 in patients with advanced heart failure, during left ventricular assist device support and following heart transplantation. BMC Cardiovasc. Disord. 2016, 16, 138. [CrossRef]

37. Lok, S.I.; Nous, F.M.; Van Kuik, J.; Van Der Weide, P.; Winkens, B.; Kemperman, H.; Huisman, A.; Lahpor, J.R.; De Weger, R.A.; De Jonge, N. Myocardial fibrosis and pro-fibrotic markers in end-stage heart failure patients during continuous-flow left ventricular assist device support. Eur. J. Cardio-Thoracic. Surg. 2015, 48, 407-415. [CrossRef]

38. Kato, T.S.; Chokshi, A.; Singh, P.; Khawaja, T.; Iwata, S.; Homma, S.; Akashi, H.; Cheema, F.H.; Yang, J.; Takayama, H.; et al. Markers of extracellular matrix turnover and the development of right ventricular failure after ventricular assist device implantation in patients with advanced heart failure. J. Hear. Lung Transplant. 2011, 31, 37-45. [CrossRef]

39. Hennig, F.; Stepanenko, A.V.; Lehmkuhl, H.B.; Kukucka, M.; Dandel, M.; Krabatsch, T.; Hetzer, R.; Potapov, E.V. Neurohumoral and inflammatory markers for prediction of right ventricular failure after implantation of a left ventricular assist device. Gen. Thorac. Cardiovasc. Surg. 2011, 59, 19-24. [CrossRef]

40. Pronschinske, K.B.; Qiu, S.; Wu, C.; Kato, T.S.; Khawaja, T.; Takayama, H.; Naka, Y.; Templeton, D.L.; George, I.; Farr, M.A.; et al. Neutrophil gelatinase- associated lipocalin and cystatin $C$ for the prediction of clinical events in patients with advanced heart failure and after ventricular assist device placement. J. Heart Lung Transplant. 2014, 33, 1215-1222. [CrossRef]

41. Tabit, C.E.; Chen, P.; Kim, G.H.; Fedson, S.E.; Sayer, G.; Coplan, M.J.; Jeevanandam, V.; Uriel, N.; Liao, J.K. Elevated Angiopoietin-2 level in patients with continuous-flow left ventricular assist devices leads to altered angiogenesis and is associated with higher nonsurgical bleeding. Circulation 2016, 134, 141-152. [CrossRef] [PubMed]

42. Patel, S.R.; Madan, S.; Saeed, O.; Algodi, M.; Luke, A.; Gibber, M.; Goldstein, D.J.; Jorde, U.P. Association of nasal mucosal vascular alterations, gastrointestinal arteriovenous malformations, and bleeding in patients with continuous-flow left ventricular assist devices. JACC Heart Fail. 2016, 4, 962-970. [CrossRef] [PubMed]

43. Kihara, S.; Litwak, K.N.; Nichols, L.; Litwak, P.; Kameneva, M.V.; Wu, Z.; Kormos, R.L.; Griffith, B.P. Smooth muscle cell hypertrophy of renal cortex arteries with chronic continuous flow left ventricular assist. Ann. Thorac. Surg. 2003, 75, 178-183. [CrossRef]

44. Bartoli, C.R.; Restle, D.J.; Zhang, D.M.; Acker, M.A.; Atluri, P. Pathologic von Willebrand factor degradation with a left ventricular assist device occurs via two distinct mechanisms: Mechanical demolition and enzymatic cleavage. J. Thorac. Cardiovas. Surg. 2015, 149, 281-289. [CrossRef] [PubMed] 
45. Bartoli, C.R.; Zhang, D.M.; Hennessy-Strahs, S.; Kang, J.; Restle, D.J.; Bermudez, C.; Atluri, P.; Acker, M.A. Clinical and In Vitro Evidence That Left Ventricular Assist Device-Induced von Willebrand Factor Degradation Alters Angiogenesis. Circ. Heart Fail. 2018, 11, e004638. [CrossRef] [PubMed]

46. Bartoli, C.R.; Spence, P.A.; Siess, T.; Raess, D.H.; Koenig, S.C.; Dowling, R.D. Non-physiologic blood flow triggers endothelial and arterial remodeling in vivo: Implications for novel left ventricular assist devices with a peripheral anastomosis. J. Thorac. Cardiovasc. Surg. 2014, 148, 311-321. [CrossRef]

47. Kang, J.; Hennessy-Strahs, S.; Kwiatkowski, P.; Bermudez, C.A.; Acker, M.A.; Atluri, P.; McConnell, P.I.; Bartoli, C.R. ContinuousFlow LVAD Support Causes a Distinct Form of Intestinal Angiodysplasia. Circ. Res. 2017, 121, 963-969. [CrossRef]

48. Starke, R.D.; Ferraro, F.; Paschalaki, K.; Dryden, N.H.; McKinnon, T.A.J.; Sutton, R.E.; Payne, E.M.; Haskard, D.O.; Hughes, A.; Cutler, D.; et al. Endothelial von Willebrand factor regulates angiogenesis. Blood 2011, 117, 1071-1080. [CrossRef]

49. Cascone, T.; Heymach, J.V. Targeting the angiopoietin/Tie2 pathway: Cutting tumor vessels with a double-edged sword? J. Clin. Oncol. 2012, 30, 441-444. [CrossRef]

50. Boyle, A.J.; Russell, S.D.; Teuteberg, J.J.; Slaughter, M.S.; Moazami, N.; Pagani, F.; Frazier, O.H.; Heatley, G.; Farrar, D.J.; John, R. Low Thromboembolism and Pump Thrombosis with the HeartMate II Left Ventricular Assist Device: Analysis of Outpatient Anti-coagulation. J. Heart Lung Transplant. 2009, 28, 881-887. [CrossRef]

51. Poredos, P.; Jezovnik, M.K.; Radovancevic, R.; Gregoric, I.D. Endothelial Function in Patients with Continuous-Flow Left Ventricular Assist Devices. Angiology 2020, 72, 9-15. [CrossRef] [PubMed]

52. Levine, B.; Kalman, J.; Mayer, L.; Fillit, H.M.; Packer, M. Elevated Circulating Levels of Tumor Necrosis Factor in Severe Chronic Heart Failure. N. Engl. J. Med. 1990, 323, 236-241. [CrossRef] [PubMed]

53. Torre-Amione, G.; Kapadia, S.; Benedict, C.; Oral, H.; Young, J.B.; Mann, D.L. Proinflammatory cytokine levels in patients with depressed left ventricular ejection fraction: A report from the Studies of Left Ventricular Dysfunction (SOLVD). J. Am. Coll. Cardiol. 1996, 27, 1201-1206. [CrossRef]

54. Markousis-Mavrogenis, G.; Tromp, J.; Ouwerkerk, W.; Devalaraja, M.; Anker, S.D.; Cleland, J.G.; Dickstein, K.; Filippatos, G.S.; Van Der Harst, P.; Lang, C.C.; et al. The clinical significance of interleukin-6 in heart failure: Results from the BIOSTAT-CHF study. Eur. J. Heart Fail. 2019, 21, 965-973. [CrossRef]

55. Masai, T.; Sawa, Y.; Ohtake, S.; Nishida, T.; Nishimura, M.; Fukushima, N.; Yamaguchi, T.; Matsuda, H. Hepatic dysfunction after left ventricular mechanical assist in patients with end-stage heart failure: Role of inflammatory response and hepatic microcirculation. Ann. Thorac. Surg. 2002, 73, 549-555. [CrossRef]

56. Caruso, R.; Trunfio, S.; Milazzo, F.; Campolo, J.; De Maria, R.; Colombo, T.; Parolini, M.; Cannata, A.; Russo, C.; Paino, R. Early expression of pro- and anti-inflammatory cytokines in left ventricular assist device recipients with multiple organ failure syndrome. ASAIO J. 2010, 56, 313-318. [CrossRef] [PubMed]

57. Lappegard, K.T.; Bergseth, G.; Riesenfeld, J.; Pharo, A.; Magotti, P.; Lambris, J.D.; Mollnes, T.E. The artificial surface-induced whole blood inflammatory reaction revealed by increases in a series of chemokines and growth factors is largely complement dependent. J. Biomed Mater. Res. A 2008, 87, 129-135. [CrossRef]

58. Takahashi, T.; Anzai, T.; Yoshikawa, T.; Maekawa, Y.; Asakura, Y.; Satoh, T.; Mitamura, H.; Ogawa, S. Serum C-reactive protein elevation in left ventricular remodeling after acute myocardial infarction-role of neurohormones and cytokines. Int. J. Cardiol. 2003, 88, 257-265. [CrossRef]

59. Tabit, C.E.; Coplan, M.J.; Chen, P.; Jeevanandam, V.; Uriel, N.; Liao, J.K. Tumor necrosis factor-alpha levels and non-surgical bleeding in continuous-flow left ventricular assist devices. J. Heart Lung Transplant. Off. Publ. Int. Soc. Heart Transplant. 2018, 37, 107-115. [CrossRef]

60. Rondina, M.T.; Weyrich, A.S.; Zimmerman, G.A. Platelets as cellular effectors of inflammation in vascular diseases. Circ. Res. 2013, 112, 1506-1519. [CrossRef]

61. Ahmad, T.; Wang, T.; O’Brien, E.C.; Samsky, M.D.; Pura, J.A.; Lokhnygina, Y.; Rogers, J.G.; Hernandez, A.F.; Craig, D.; Bowles, D.E.; et al. Effects of Left Ventricular Assist Device Support on Biomarkers of Cardiovascular Stress, Fibrosis, Fluid Homeostasis, Inflammation, and Renal Injury. JACC Heart Fail. 2015, 3, 30-39. [CrossRef] [PubMed]

62. Saito, S.; Westaby, S.; Piggot, D.; Dudnikov, S.; Robson, D.; Catarino, P.A.; Clelland, C.; Nojiri, C. End-organ function during chronic nonpulsatile circulation. Ann. Thorac. Surg. 2002, 74, 1080-1085. [CrossRef]

63. Welp, H.; Rukosujew, A.; Tjan, T.D.; Hoffmeier, A.; Kösek, V.; Scheld, H.H.; Drees, G. Effect of pulsatile and non-pulsatile left ventricular assist devices on the renin-angiotensin system in patients with end-stage heart failure. Thorac. Cardiovasc. Surg. 2010, 58 (Suppl. 2), S185-S188. [CrossRef]

64. Grosman-Rimon, L.; McDonald, M.A.; Jacobs, I.; Tumiati, L.C.; Pollock Bar-Ziv, S.; Shogilev, D.J.; Mociornita, A.G.; Ghashghai, A.; Chruscinski, A.; Cherney, D.Z.; et al. Markers of inflammation in recipients of continuous-flow left ventricular assist devices. ASAIO J. 2014, 60, 657-663. [CrossRef] [PubMed]

65. Dominguez-Rodriguez, A.; Abreu-Gonzalez, P.; Garcia-Gonzalez, M.; Ferrer, J. Prognostic value of interleukin-8 as a predictor of heart failure in patients with myocardial infarction and percutaneous intervention. Int. J. Cardiol. 2006, 111, 158-160. [CrossRef] [PubMed]

66. Maekawa, Y.; Anzai, T.; Yoshikawa, T.; Sugano, Y.; Mahara, K.; Kohno, T.; Takahashi, T.; Ogawa, S. Effect of granulocytemacrophage colony-stimulating factor inducer on left ventricular remodeling after acute myocardial infarction. J. Am. Coll. Cardiol. 2004, 44, 1510-1520. [CrossRef] [PubMed] 
67. Hein, T.W.; Singh, U.; Vasquez-Vivar, J.; Devaraj, S.; Kuo, L.; Jialal, I. Human C-reactive protein induces endothelial dysfunction and uncoupling of eNOS In Vivo. Atherosclerosis 2009, 206, 61-68. [CrossRef]

68. Wassmann, S.; Stumpf, M.; Strehlow, K.; Schmid, A.; Schieffer, B.; Böhm, M.; Nickenig, G. Interleukin-6 induces oxidative stress and endothelial dysfunction by overexpression of the angiotensin II type 1 receptor. Circ. Res. 2004, 94, 534-541. [CrossRef]

69. Walenga, J.M.; Torres, T.A.; Jeske, W.P.; Schwartz, J.; Escalante, V.; Newman, J.D.; Bakhos, M. Protein C Pathway, Inflammation, and Pump Thrombosis in Patients with Left Ventricular Assist Devices. Clin. Appl. Thromb. 2020, 26, 1076029620959724. [CrossRef]

70. Grosman-Rimon, L.; Jacobs, I.; Tumiati, L.C.; McDonald, M.A.; Bar-Ziv, S.P.; Fuks, A.; Kawajiri, H.; Lazarte, J.; Ghashghai, A.; Shogilev, D.J.; et al. Longitudinal assessment of inflammation in recipients of continuous-flow left ventricular assist devices. Can. J. Cardiol. 2015, 31, 34. [CrossRef] 